\title{
Development of anti-corrosive paint incorporated with henna extract as a natural inhibitor
}

\author{
W.B. Wan Nik ${ }^{1}$, H.M. Hajar' ${ }^{1}$ M.J. Suriani ${ }^{1}$, M.G.M. Sabri' ${ }^{2}$ and M.J. Ghazali ${ }^{3}$ \\ ${ }^{1}$ School of Ocean Engineering, Universiti Malaysia Terengganu, \\ 21030 Kuala Nerus, Terengganu, Malaysia \\ ${ }^{2}$ School of Fundamental Science, Universiti Malaysia Terengganu, \\ 21030 Kuala Nerus, Terengganu, Malaysia \\ ${ }^{3}$ Department of Mechanical \& Materials Engineering, Faculty of Engineering \& \\ Built Environment, Universiti Kebangsaan Malaysia, \\ 43600 UKM Bangi, Selangor, Malaysia \\ *Email: niksani@umt.edu.my \\ Phone: +6096683342; Fax: +6096683991
}

\begin{abstract}
Metallic materials are the most applicable materials in various industries. They are useful due to their excellent mechanical properties. However, they are exposed to corrosion because the environment contains oxygen, humidity and some other factors. This paper describes about a paint incorporated with organic inhibitor, i.e., henna extract. This paint was produced to enhance its anticorrosive property. Henna extract was chosen as the corrosion inhibitor as it is organic, environmentally acceptable, readily available and a renewable source of material for a wide range of corrosion problems. The extractions were characterised by using Fourier Transform Infrared. Meanwhile, the inhibitive action of henna extract was investigated through an electrochemical technique. The inhibitive effects of henna extract were investigated with percentages of $0 \%, 4 \%, 8 \%$ and $10 \%$ incorporated into a rosin (epoxy)-based matrix. The specimens were characterised by electrochemical impedance spectroscopy measurement. The morphology study was investigated through surface analysis by using scanning electron microscopy. The inhibition efficiency increased as the concentration of henna extract was increased. The results showed that Paint 3 has the lowest corrosion rate of 0.001767 $\mathrm{mm} / \mathrm{yr}$ as compared to Paint 1 with $0.005148 \mathrm{~mm} / \mathrm{yr}$. The inhibitive action of the henna extract is discussed. Paint 3 was proposed as the most effective paint that contains a natural inhibitor for aluminium alloy.
\end{abstract}

Keywords: Coating; EIS; organic inhibitor.

\section{INTRODUCTION}

The application of metals and alloys in most industries is very important, especially in construction. Industries that are involved are the automotive, building construction and marine sectors. However, the marine industry is the most affected industry due to the exposure of metals towards seawater and humidity. Marine environment is very synonymous with the aggressive environment and causes the deterioration of metals or alloys. Marine structures, such as jetties, oil and gas platforms and parts of a ship body, are the most affected parts of the corrosion problem [1]. Corrosion is the biggest 
contributing factor of marine structural failures through loss of structural strength at a local and global level [2].Historically, traditional paints use tributyltin (TBT) as an ingredient in marine paint due to its excellent performance. However, it was strictly restricted since 1982 to protect oyster growth [3]. Nowadays, great attention is focused on the use of natural corrosion inhibitors to reduce metals and alloys deterioration. This method is very practical for corrosion protection and it also decreases hydrogen evolution [4]. Inhibitors are substances or mixtures that are applied in low concentration and used in an aggressive environment to inhibit, prevent or minimise pitting or localised corrosion [5]. Corrosion inhibitors can be organic or inorganic and are classified by the mechanism of action as anodic, cathodic or an anodic-cathodic mix and by adsorption action or act as oxidants or anti-oxidants (Figure 1) [6].

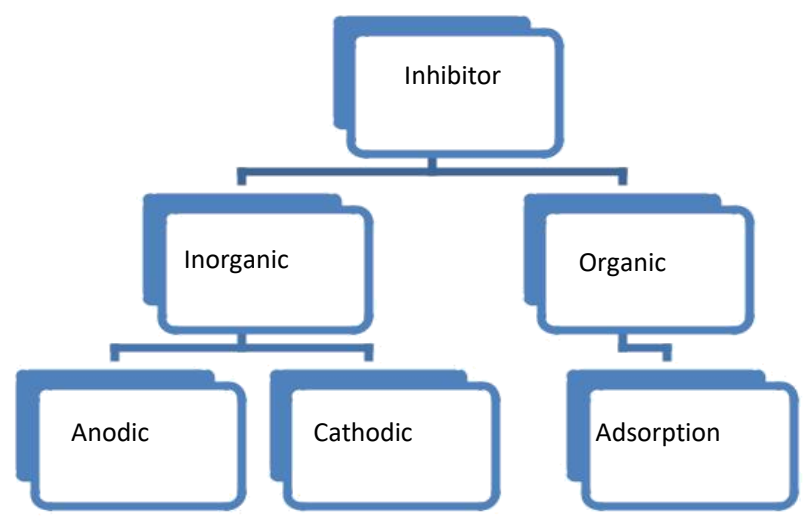

Figure 1. Inhibitors classification.

The addition of inhibitors helps metals or alloys to maintain their resistance against corrosion. This phenomenon occurs due to various inhibition mechanisms produced [7]. The application of a corrosion inhibitor is not only limited by incorporating into the paint but it may also be added during the production process, such as drilling for offshore work [8]. Recent research were focused on the plant extracts as natural sources of corrosion inhibitor due to their potential in corrosion inhibition. Other than that, natural sources are readily available, ecologically acceptable, cheap, renewable and also environmental friendly $[9,10]$. In this study henna plant extract was chosen in an attempt to investigate its potential as a corrosion inhibitor. In previous studies, researchers investigated about the corrosion inhibition of henna extract with different metals and solutions. Some researchers improved the corrosion protection properties by incorporating active corrosion inhibitors into coatings. Henna extract was incorporated into rosin-based paint. Rosin is a gum derived from the exudation of pine trees, which acts as a binder in a coating matrix [11]. In addition, the incorporation of inhibitors into paint is for self-healing effect in the coatings [12]. The inhibitive actions of henna extract were investigated in present studies due to their cheap, eco-friendly and natural occurring substance [13]. The aim of this study is to evaluate the inhibition corrosion potential of henna extract, incorporated into paint, to produce an anticorrosive paint. Inhibited aluminium surfaces were examined with scanning electron microscopy (SEM) while the protective film was subjected to Fourier Transform Infrared Spectroscopy (FTIR) analysis. The weight loss study and electrochemical impedance spectroscopy (EIS) were performed to investigate the inhibitive action of henna extract. 


\section{MATERIALS AND METHODS}

\section{Preparation of Specimens}

Aluminium alloy (AA5083) specimens were used for this study due to their extensive usage in marine industry, particularly as a plate for ship building. The specimen were cut into square shapes with dimension of $25 \mathrm{~mm}$ x $25 \mathrm{~mm} \times 3 \mathrm{~mm}$. The AA5083 has percentage composition of $0.40 \% \mathrm{Si}, 0.40 \% \mathrm{Fe}, 0.10 \% \mathrm{Cu}, 0.40-1.0 \% \mathrm{Mn}, 4.0-4.9 \%$ $\mathrm{Mg}, 0.05-0.25 \% \mathrm{Cr}, 0.25 \% \mathrm{Zn}$ and $0.15 \% \mathrm{Ti}$. The specimens were polished with 400 , 800 and 1200 grit of abrasive paper. The polished specimens were cleaned by using acetone (according to SSPC-SP1 Standard) to remove all visible oil, grease, soil, drawing and cutting compounds, and other soluble contaminants. To provide good adhesion between the primer and metallic substrate, the cleaning process is very important. The specimens were then coated with epoxy-based paint. There are four types of paints used in this study, in which Paint 1 (without henna extract) acts as the control paint. Besides that, there are Paint 2, Paint 3, and Paint 4. The paints were diluted with $4 \%, 8 \%$, and $10 \%$ of henna extract, respectively. The experiment was conducted for 60 days.

\section{Extraction Preparation}

The commercial henna powders were purchased at a local market and it was mixed with ethanol solution. Then it was left for 7-day daily agitation. The ethanol extract was filtered by Whatman filter paper, The remaining filtrates were collected and heated in a water bath at $48^{\circ} \mathrm{C}$ to evaporate its liquids content. Ethanol was removed from the henna extractions by using rotary evaporations (ROTAVAP). The remaining residues were stored at room temperature [14] until it was ready for use.

\section{Paint Preparation}

WW rosin type resin (colophony) was used as a binder and oleic acid as the plasticiser. The paint was prepared by using a magnetic stirrer to blend all the ingredients together and also to achieve an efficient dispersion. WW rosin and oleic acid were dissolute in a xylene/white spirit mixture $(1: 1)$ by using a high speed disperser. The ingredients were then mixed with the pigments and additives (zinc oxide and calcium carbonate), and dispersed for 24 hours [15]. For the anticorrosion paints (Paint 2, Paint 3 and Paint 4), the henna extract was incorporated into the matrix paint and dispersed for 5 hours. After 5 hours, the paint was ready for coating. The coated samples were scratched with ' $\mathrm{X}$ ' mark to assess the paint coatings resistance towards separation from substrates [16] since the immersion period was only 60 days and this method was referred to the ASTM D7187-15.

\section{Weight Loss Measurement}

The coated specimens with different $\%$ of henna extract were weighed and suspended in seawater solution. The experiments were carried out at ambient temperature and they were immersed for 60 days [14]. Every 12 days, the specimens were withdrawn and washed by using nitric acid for 2-3 minutes and cleaned with distilled water, dried and weighed again to obtain the final weight. The experiment was conducted in a fume cupboard at room temperature. 


\section{Fourier Transform Infrared}

Fourier Transform Infrared (FTIR) was carried out by using Thermo Nicolet 380 FTIR spectrometer at the Organic Chemistry Laboratory, in Universiti Malaysia Terengganu. A drop of henna extract was placed on the sample holder with the sample cap of diffused reflectance accessory. The extract was exposed under a range of infrared rays beams and the sensor below the platform would sense the frequency, either reflected or absorbed. The liquid transmittance and reflectance of the infrared rays at different frequencies were translated into an IR absorption plot consisting of reverse peaks.

\section{Electrochemical Measurement}

For electrochemical measurement, the test was conducted to measure the impedance of a system over a range of frequencies according to the ASTM STP 1188. The Autolab software was used by conducting Autolab PGSTAT 302N. This device was connected to a computer to obtain useful data. Frequency Response Analyser (FRA) was used for analysing data. A scanning rate $0.0101 \mathrm{Vs}^{-1}$ was set and the electrode potential was automatically changed from $-0.5 \mathrm{mV}$ to $+0.5 \mathrm{mV}$ and it was then represented in Nyquist plot.

\section{Scanning Electron Microscopy}

The effect of inhibitor on corrosion process of AA5083 was investigated by using scanning electron microscope (SEM) technique according to the ASTM F1877-16, a standard practice for particles characterisation. The images were recorded by using JSM6390LA SEM, after the exposure test. The specimens need to be coated with gold powder to aid in the specimen's surface conductivity.

\section{RESULTS AND DISCUSSION}

\section{Fourier Transform Infrared}

The results in Figure 1 were confirmed by Fourier Transform Infrared (FTIR) spectra of henna extract. The main constituent of henna extract is lawsone (Figure 2), which contains benzene unit, p- benzoquinone unit and phenolic group [13]. Other than that, the three major functional groups that can be derived from the structure were phenols $\mathrm{O}-\mathrm{H}$, ketone $\mathrm{C}=\mathrm{O}$ and alkenes $\mathrm{C}=\mathrm{C}[17]$. These three groups were also known as flavanoids [18]. The phenolic group $(\mathrm{O}-\mathrm{H})$ stretch appeared at $3353.5 \mathrm{~cm}^{-1}$. The peaks at $2855.3 \mathrm{~cm}^{-1}$ and $819.6 \mathrm{~cm}^{-1}$ can be considered as aliphatic and aromatic $\mathrm{C}-\mathrm{H}$. The aromatic $\mathrm{C}=\mathrm{C}$ stretching frequency appeared at $1656.1 \mathrm{~cm}^{-1}$. The ketone group $(\mathrm{C}=\mathrm{O})$ stretching frequency appeared at $1711.9 \mathrm{~cm}^{-1}$ and $1696.7 \mathrm{~cm}^{-1}$. The presence of phenol group of lawsone contributed to the electron donation to the metal to achieve its noble state of orbit. The metal becomes more stable as it received the electron [12]. The double carbon bond indicated good corrosion resistance in the henna extracts [19]. Previous work has reported that the main components of henna extract were hydroxyl aromatic compounds such as tannin and lawsone, and they were attributed to the formation of passivating layer tannates on the metal surface and due to these reasons they were used in the manufacturing of anti-rusting paints and coating [20].

\section{Weight Loss Measurement}

The weight loss measurements for Paint 1, Paint 2, Paint 3 and Paint 4 for 60 days immersion are given in Figure 3. The presence of inhibitor shows a decreasing value of weight loss against time of immersion. It is indicated that the increase of henna extract 
incorporated into paint led to a decrease in specimen weight loss. This finding can be related from the FTIR result obtained, which is the amount of lawsone structure present in the paint composition [13]. Table 1 shows the readings of weight losses and the corrosion rate of specimens after 60 days immersion in seawater. Paint 3 shows the smallest value of the weight loss of about $0.69 \%$ as compared to the Paint 1(without inhibitor) which is $2.10 \%$. On the other hand, corrosion rate for Paint 1 is 0.005148 $\mathrm{mm} / \mathrm{yr}$ and the reading shows a subsequent decrease to $0.001767 \mathrm{~mm} / \mathrm{yr}$ with increasing henna extraction.

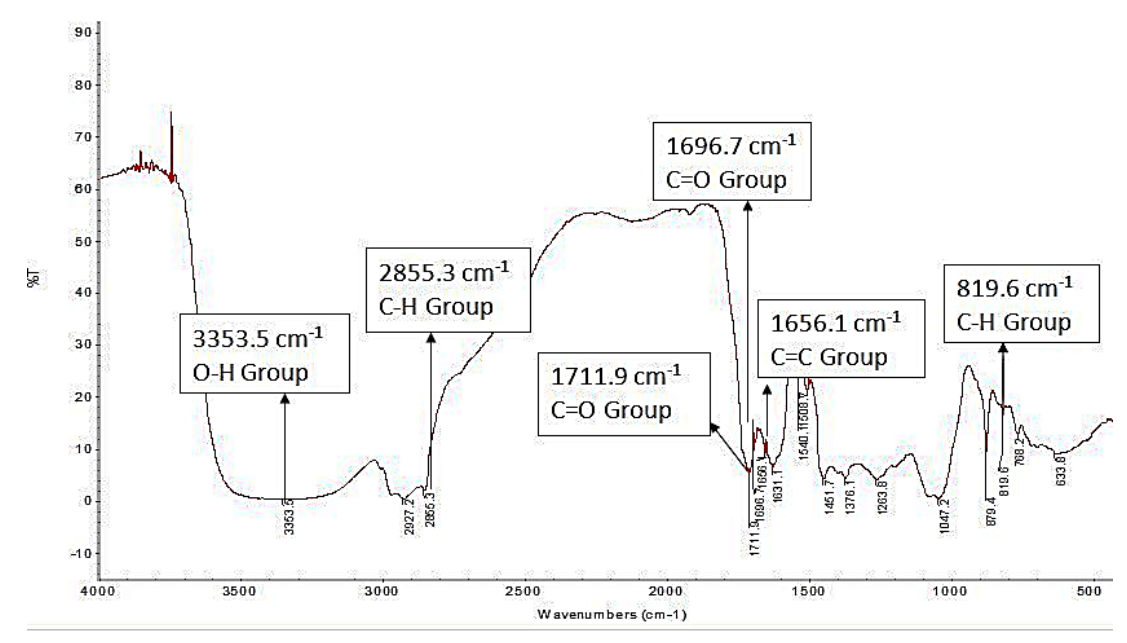

Figure 2. IR spectra for henna extraction by using FTIR analysis.

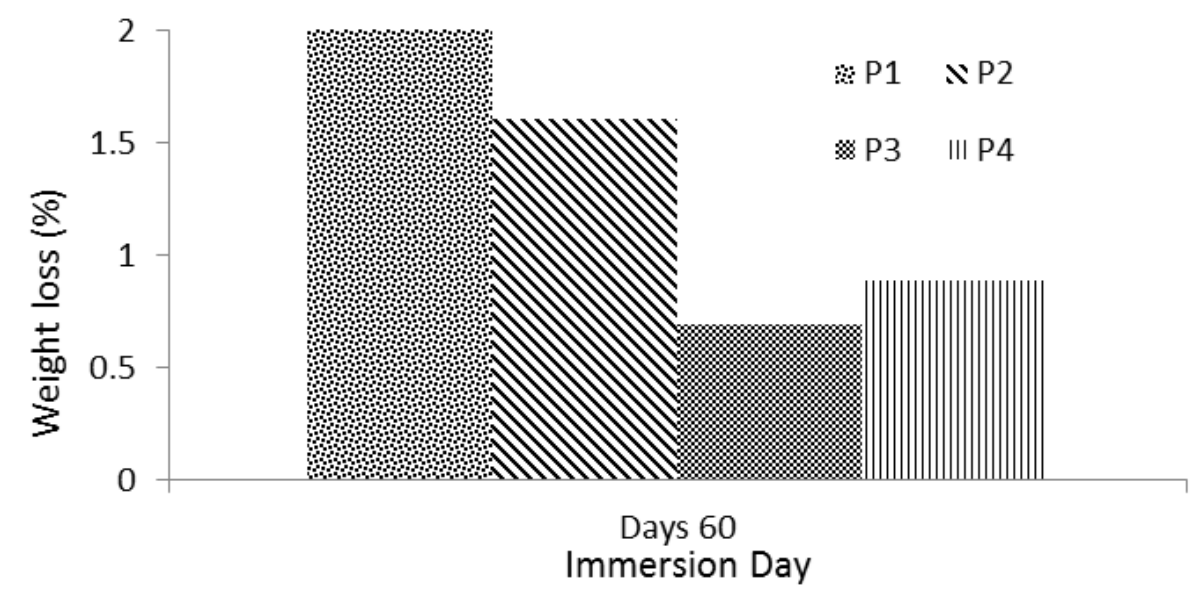

Figure 3. Bar chart of the weight losses for Paint 1, Paint 2, Paint 3 and Paint 4 for 60 days immersion.

Table 1. Parameter of weight loss (\%) and corrosion rate of specimens after 60 days of immersion.

\begin{tabular}{lcc}
\hline Type of paint & Weight loss $(\%)$ & Corrosion rate $(\mathrm{mm} / \mathrm{yr})$ \\
\hline Paint 1 (P1) & 2.10 & 0.005148 \\
Paint 2 (P2) & 1.60 & 0.003846 \\
Paint 3 (P3) & 0.69 & 0.001767 \\
Paint 4 (P4) & 0.88 & 0.002129 \\
\hline
\end{tabular}




\section{Inhibition Efficiency}

The values of the inhibition efficiency, IE (\%) from the weight loss test were calculated by using Equation (1):

$$
\operatorname{IE}(\%)=100\left(1-W / W_{0}\right)
$$

where $W_{0}$ and $W$ are the weight loss in the absence and the presence of inhibitor.

The analyses of the IE (\%) values are given in Table 2 . The IE increases with the increasing of the henna extract incorporated into paint. The value of the IE (\%) increases due to the adsorption of the inhibitor molecules on the specimen/solution interface where the adsorbed molecules mechanically screen the coated part of the metal surface from the action of the corrodent [21]. For EIS measurements, the percentage of inhibition efficiency was calculated using $R p$ values through Equation (2):

$$
\operatorname{IE}(\%)=100\left(1-R_{p(0)} / R_{p}\right)
$$

where $R_{p(0)}$ and $R_{p}$ are the polarisation resistance values in the absence and presence of inhibitor.

Table 2. IE (\%) values from weight loss and EIS technique.

\begin{tabular}{ccc}
\hline Types of paint & \multicolumn{2}{c}{ IE (\%) } \\
\hline & Weight loss & EIS \\
\hline P1 & - & - \\
P2 & 31.63 & 79.51 \\
P3 & 77.75 & 96.25 \\
P4 & 69.39 & 53.69 \\
\hline
\end{tabular}

IE from EIS method shows that P3 is the most efficient paint as compared to others. This occurrence maybe due to the limitation of henna extract itself. This may be explained by the presence of more ions which hinders the absorption of dye to fibre where rare ions favour it and it has mentioned that due to the increment of henna concentration, the absolute quantity is diminished [22]. On the other hand, there is a report about the limitation of the henna extract can be incorporated into paint matrix where the presence of more inhibitor ions hinders the adsorption to the metal surface. This is related to the inhibition performance of henna extract decreases when it reaches a certain amount in a paint system due to the shift of a certain functional group present in lawsone structure [23].

\section{Electrochemical Impedance Spectroscopy}

The corrosion behaviours of the specimens with four different percentages of henna extracts immersed in seawater were investigated by using Electrochemical Impedance Spectroscopy. The data obtained were represented in Nyquist plots (Figure 4). The features of all impedance spectra exhibit a similar shape. The single capacitive semicircle shows the corrosion process was mainly charge transfer controlled [24]. The results show that the presence of henna extract increases polarisation resistance $\left(R_{p}\right)$ value from $1792.2 \Omega . \mathrm{cm}^{2}$ to $47783 \Omega . \mathrm{cm}^{2}$ and decreases to $3870.4 \Omega . \mathrm{cm}^{2}$ when $10 \%$ of 
henna extract was added into matrix paint. The increment in the $R_{p}$ value leads to an increase in inhibition efficiency. As the percentage of henna extract increases, the value of $R_{p}$ increases as well due to the formation of passive films. Double layer capacitance $\left(C_{d l}\right)$ decreases from $0.003793 \mathrm{~F}$ to $0.000283 \mathrm{~F}$.

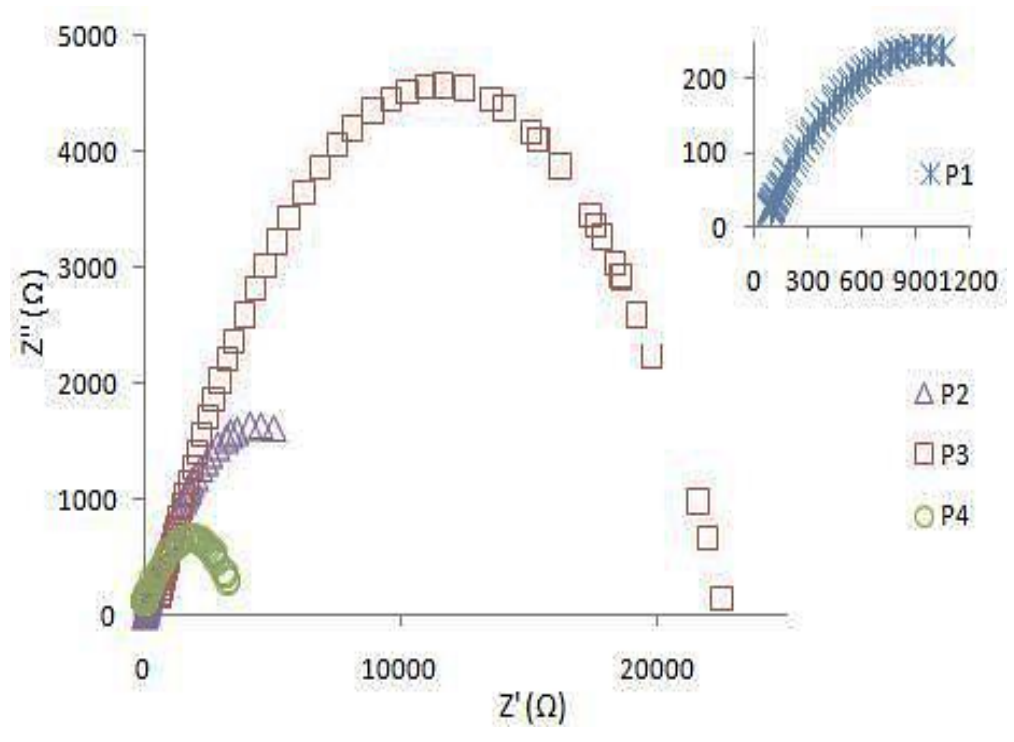

Figure 4. Nyquist plot of specimen immersed in seawater for 60 days.

Paint 1 (without inhibitor) was observed to have a small semi-circle as compared to others with the $R_{p}$ value was only $1792.20 \Omega$. This indicates that the inhibition is mainly affected by charge transfer and once the surface is covered by inhibitor molecules, some competitive diffusion resistance is taking place between the molecules to reach metal surface [6]. Other than that, as the value of $C_{d l}$ decreased, it resulted in a decrease in local dielectric constant and/or an increase in the thickness of the double layer capacitance.
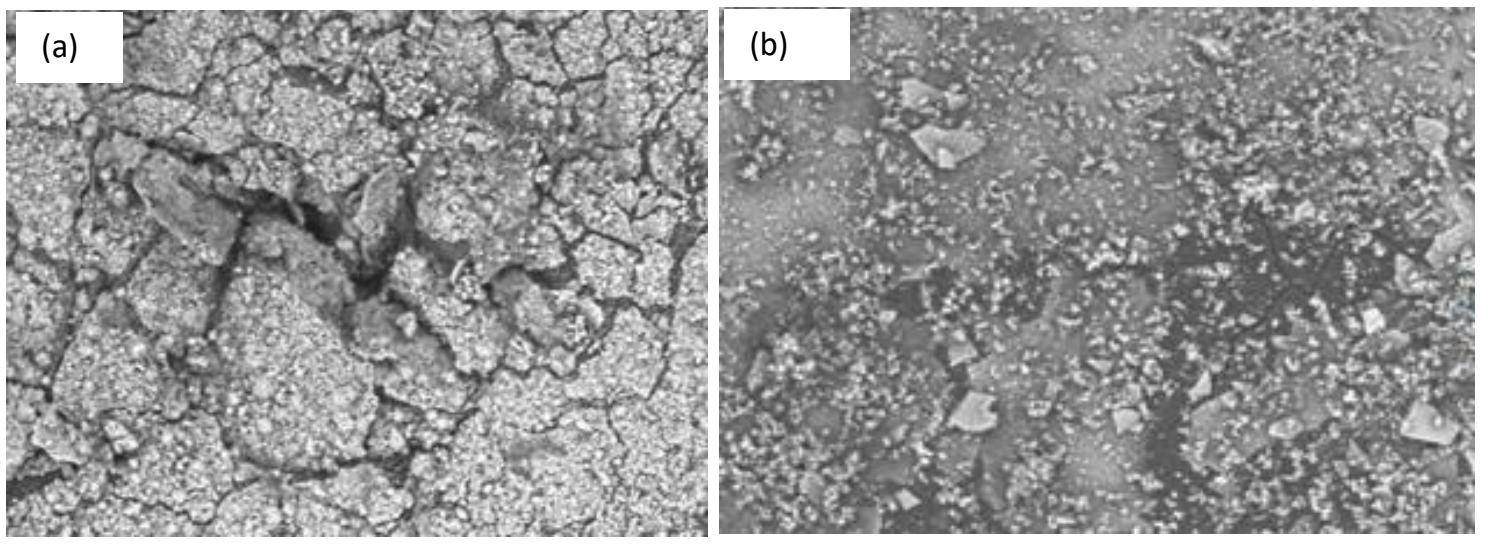

Figure 5. (a) Paint 1 and (b) Paint 3 after 60 days of immersion in seawater.

\section{Scanning Electron Microscope}

In order to study the corrosion phenomena on the specimen's surface, Scanning Electron Microscope (SEM) analysis was carried out. Figure 5 shows the SEM analysis after 60 days of immersion in seawater. Other than that, corrosion was produced due to the 
exposure of the substrate after electrochemical testing [25]. By comparing the SEM images at the same magnification, it was observed that the surface was very rough and severely damage as shown in Figure 5, which represents the surface of specimen without inhibitor. The surface is smoother and with more uniform deposits with the addition of $4 \%$ of henna extract. Therefore, it can be assumed that the formation of inhibitors in paint system also had contributed to the inhibitive action by forming a protective film on the substrate surface [26].

\section{CONCLUSIONS}

Based on the investigation, henna extract acts as a good inhibitor for the corrosion of aluminium alloy 5083 in seawater. This is due to the high inhibition efficiency produced. From the EIS study, the incorporation of henna extract into matrix paint had provided a barrier with the inhibition efficiency recorded to be $96.25 \%$. Based on the observations, the inhibition efficiency of inhibitor increased with increasing of henna extract. In the presence of henna extract, the value of $R_{p}$ increases and the value of $C_{d l}$ decreases. P3 is shown to be the most efficient paint due to the inhomogeneity in coating sample as the henna percentage increased. The FTIR shows that the compounds present in the henna extract form a corrosion inhibitive layer and the inhibitor can be adsorbed on the metal surface through oxygen atom of lawsone, which is the main constituent present in henna extract. In the absence of henna extract, the surface of specimen is very rough and damages could be observed on its surface whereas the surface gets smoother and more uniform in the presence of henna extract.

\section{ACKNOWLEDGEMENTS}

The authors would like to express their deepest gratitude for the funds provided by Ministry of Education, Malaysia (Look East Policy 2.0, vot 53168). The authors greatly acknowledge Miss Suria Hani for her direct contribution during the preparation of this manuscript.

\section{REFERENCES}

[1] Chambers LD, Stokes KR, Walsh FC, Wood RJK. Modern approaches to marine antifouling coatings. Surface and Coatings Technology. 2006;201:3642-52.

[2] De Baere K, Verstraelen H, Rigo P, Van Passel S, Lenaerts S, Potters G. Study on alternative approaches to corrosion protection of ballast tanks using an economic model. Marine Structures. 2013;32:1-17.

[3] Hellio C, De La Broise D, Dufossé L, Le Gal Y, Bourgougnon N. Inhibition of marine bacteria by extracts of macroalgae: potential use for environmentally friendly antifouling paints. Marine Environmental Research. 2001;52:231-47.

[4] Ameer MA, Fekry AM. Corrosion inhibition of mild steel by natural product compound. Progress in Organic Coatings. 2011;71:343-9.

[5] Obot IB, Obi-Egbedi NO, Umoren SA. Antifungal drugs as corrosion inhibitors for aluminium in 0.1M HCl. Corrosion Science. 2009;51:1868-75.

[6] G C, F A. Corrosion Inhibitors - Principles, Mechanisms and Applications. In: Aliofkhazraei M, editor. Developments in Corrosion Protection: InTech; 2014. 
[7] Ibrahim TH, Chehade Y, Zour MA. Corrosion inhibition of mild steel using potato peel extract in 2M HCL solution. International Journal of Electrochemical Science. 2011;6:6542-56.

[8] Scott PJB, Davies M. Retroactive determination of industrial contaminants in tropical marine communities. Marine Pollution Bulletin. 1997;34:975-80.

[9] Buchweishaija J. Plants as a source of green corrosion inhibitors: the case of gum exudates from Acacia species (A. drepanolobium and A. senegal). Tanzania Journal of Science. 2009;35.

[10] Odewunmi NA, Umoren SA, Gasem ZM. Watermelon waste products as green corrosion inhibitors for mild steel in $\mathrm{HCl}$ solution. Journal of Environmental Chemical Engineering. 2015;3:286-96.

[11] Olad A, Barati M, Behboudi S. Preparation of PANI/epoxy/Zn nanocomposite using $\mathrm{Zn}$ nanoparticles and epoxy resin as additives and investigation of its corrosion protection behavior on iron. Progress in Organic Coatings. 2012;74:221-7.

[12] Motalebi A, Nasr-Esfahani M, Ali R, Pourriahi M. Improvement of corrosion performance of 316L stainless steel via PVTMS/henna thin film. Progress in Natural Science: Materials International. 2012;22:392-400.

[13] Hamdy A, El-Gendy NS. Thermodynamic, adsorption and electrochemical studies for corrosion inhibition of carbon steel by henna extract in acid medium. Egyptian Journal of Petroleum. 2013;22:17-25.

[14] Nik WBW, Zulkifli F, Sulaiman O, Samo KB, Rosliza R. Study of Henna (Lawsonia inermis) as Natural Corrosion Inhibitor for Aluminum Alloy in Seawater. IOP Conference Series: Materials Science and Engineering. 2012;36:012043.

[15] Pérez M, García M, Ruiz D, Autino JC, Romanelli G, Blustein G. Antifouling activity of green-synthesized 7-hydroxy-4-methylcoumarin. Marine Environmental Research. 2016;113:134-40.

[16] Ahmad R, Ajer MR. Investigation of epoxy powder coated galvanized steel substrate through electrostatic powder coating system. International Journal of Automotive and Mechanical Engineering. 2015;11:2622-38.

[17] Kumar S, Singh YV, Singh M. Agro-history, uses, ecology and distribution of henna (Lawsonia inermis L. syn. Alba Lam). Henna: Cultivation, Improvement, and Trade Jodhpur: Central Arid Zone Research Institute. 2005:11-2.

[18] Gapsari F, Soenoko R, Suprapto A, Suprapto W. Bee Wax Propolis Extract as Eco-Friendly Corrosion Inhibitors for 304SS in Sulfuric Acid. International Journal of Corrosion. 2015;2015:1-10.

[19] Raja PB, Sethuraman MG. Natural products as corrosion inhibitor for metals in corrosive media - A review. Materials Letters. 2008;62:113-6.

[20] El-Etre AY, Abdallah M, El-Tantawy ZE. Corrosion inhibition of some metals using lawsonia extract. Corrosion science. 2005;47:385-95.

[21] Rosliza R, Wan Nik WB, Senin HB. The effect of inhibitor on the corrosion of aluminum alloys in acidic solutions. Materials Chemistry and Physics. 2008;107:281-8.

[22] Alam M, Rahman M, Haque M. Extraction of henna leaf dye and its dyeing effects on textile fibre. Bangladesh Journal of Scientific and Industrial Research. 2007;42(2):217-22. 
[23] Fariba B, Hassan R, Homeyra E. In vitro study of the effects of henna extracts (Lawsonia inermis) on Malassezia species. Jundishapur Journal of Microbiology. 2010;2010:125-8.

[24] Abdollahi R, Shadizadeh SR. Effect of acid additives on anticorrosive property of henna in regular mud acid. Scientia Iranica. 2012;19:1665-71.

[25] Abd Razak NA, Ng SS. Investigation of effects of MIG welding on corrosion behaviour of AISI 1010 carbon steel. Journal of Mechanical Engineering and Sciences. 2014;7:1168-78.

[26] Huang D, Hu J, Song G-L, Guo X. Inhibition effect of inorganic and organic inhibitors on the corrosion of $\mathrm{Mg}-10 \mathrm{Gd}-3 \mathrm{Y}-0.5 \mathrm{Zr}$ alloy in an ethylene glycol solution at ambient and elevated temperatures. Electrochimica Acta. 2011;56:10166-78. 